\title{
Pancreatic duct replication is increased with obesity and type 2 diabetes in humans
}

\author{
A. E. Butler • R. Galasso • A. Matveyenko • \\ R. A. Rizza $\cdot$ S. Dry $\cdot$ P. C. Butler
}

Received: 14 May 2009 / Accepted: 15 September 2009 /Published online: 21 October 2009

(C) The Author(s) 2009. This article is published with open access at Springerlink.com

\begin{abstract}
Aims/hypothesis In a high-fat-fed rat model of type 2 diabetes we noted increased exocrine duct replication. This is a predisposing factor for pancreatitis and pancreatic cancer, both of which are more common in type 2 diabetes. The aim of the study reported here was to establish if obesity and/or type 2 diabetes are associated with increased pancreatic ductal replication in humans.

Methods We obtained pancreas at autopsy from 45 humans, divided into four groups: lean (BMI $<25 \mathrm{~kg} / \mathrm{m}^{2}$ ); obese (BMI $\left.>27 \mathrm{~kg} / \mathrm{m}^{2}\right)$; non-diabetic; and with type 2 diabetes. Pancreases were evaluated after immunostaining for the duct cell marker cytokeratin and Ki67 for replication.

Results We show for the first time that both obesity and type 2 diabetes in humans are associated with increased pancreatic ductal replication. Specifically, we report that (1) replication of pancreatic duct cells is increased tenfold by obesity, and (2) lean subjects with type 2 diabetes demonstrate a fourfold increase in replication of pancreatic duct cells compared with their lean non-diabetic controls. Conclusions/interpretation Pancreatic duct cell replication is increased in humans in response to both obesity and type
\end{abstract}

A. E. Butler · R. Galasso • A. Matveyenko P. C. Butler $(\bowtie)$

Larry Hillblom Islet Research Center,

UCLA David Geffen School of Medicine,

900 Weyburn Place \#A,

Los Angeles, CA 90024-2852, USA

e-mail: pbutler@mednet.ucla.edu

R. A. Rizza

Endocrine Research Unit, Mayo Medical College,

Rochester, MN, USA

S. Dry

Department of Pathology,

UCLA David Geffen School of Medicine,

Los Angeles, CA, USA
2 diabetes, potentially providing a mechanism for the increased risk of pancreatitis and pancreatic cancer in those with obesity and/or type 2 diabetes.

Keywords DPP-IV inhibitor · GLP-1 · Obesity · Pancreatic cancer Pancreatic ductal $\cdot$ Pancreatitis
Abbreviations
HIP Human islet amyloid polypeptide transgenic
FPG Fasting plasma glucose
GLP-1 Glucagon-like peptide 1

\section{Introduction}

The incidence of pancreatitis and pancreatic cancer is increased with obesity $[1,2]$. Although the mechanism underlying this association is unknown, as the incidence of several other malignancies is increased with obesity [3], it has been considered to be a possible consequence of chronic inflammation. We reported increased pancreatic duct cell replication in Sprague-Dawley human islet amyloid polypeptide transgenic (HIP) rats fed a high-fat diet [4]. HIP rats are a model of type 2 diabetes [5, 6]. In common with type 2 diabetes, the HIP rat develops diabetes because of impaired beta cell function and loss of beta cell mass through endoplasmic-reticulum-stress-induced apoptosis.

We also noted that pancreatic duct cell replication in the high-fat-fed HIP rat increased as a function of blood glucose. While pancreatitis and pancreatic cancer can cause diabetes, there is some evidence to suggest that the converse may be true $[1,2]$. A possible underlying mechanism to account for an increased risk of pancreatic 
cancer in people with obesity and/or diabetes is chronically increased pancreatic duct cell replication. Increased pancreatic duct cell replication is a characteristic of both pancreatitis and pancreatic cancer [7-9].

We sought to address the following hypotheses. First, that pancreatic duct cell replication is increased in obese vs lean humans. Second, that pancreatic duct cell replication is increased in humans with type 2 diabetes compared with non-diabetic individuals. To address these hypotheses we examined the frequency of pancreatic duct cell replication in pancreas obtained at autopsy from lean and obese humans with or without type 2 diabetes. In addition we studied pancreas obtained at surgery from nine individuals who underwent pancreatic surgery for resection of pancreatic ductal adenocarcinoma (eight cases) and an intraductal papillary mucinous neoplasm (one case). The surgical tissue studied from each case was not from the tumour itself but from adjacent pancreas. In seven cases the pancreas was negative for tumour but did show signs of chronic pancreatitis. In two cases there was invasive adenocarcinoma in the sample.

\section{Methods}

Design and case selection Internal Review Board approval was obtained from both the Mayo Clinic and UCLA. Human pancreatic tissue, collected at autopsy, was obtained from four groups: lean non-diabetic individuals; lean individuals with type 2 diabetes; obese non-diabetic individuals; and obese individuals with type 2 diabetes. Potential cases were first identified by retrospective analysis of the Mayo Clinic autopsy database. The autopsy cases are a subgroup of those previously used to investigate a deficit in beta cells in type 2 diabetes [10]. This study therefore reflects the population of Minnesota at the time these patients died, which was predominantly $(\sim 98 \%)$ of northern European origin. To be included, cases were required to have: (1) had a full autopsy within $24 \mathrm{~h}$ of death; (2) had a general medical examination, including at least one fasting glucose documented in the year before death; and (3) pancreatic tissue stored that was of adequate size and quality. Cases were excluded if: (1) potential secondary causes of type 1 or type 2 diabetes were present; (2) patients had been exposed to chronic glucocorticoid treatment; or (3) pancreatic tissue had undergone autolysis or showed evidence of pancreatitis. Inclusion in the lean subgroup required a BMI $<25 \mathrm{~kg} / \mathrm{m}^{2}$, while inclusion in the obese subgroup required a BMI $>27 \mathrm{~kg} / \mathrm{m}^{2}$. Cases were further classified as non-diabetic (fasting plasma glucose $[\mathrm{FPG}]<6.1 \mathrm{mmol} / \mathrm{l}$ ) or with diabetes $(\mathrm{FPG}>7 \mathrm{mmol} / \mathrm{l})$. Type 2 diabetes vs other forms of diabetes was evaluated based on the clinical diagnosis of the patient attending the
Mayo Clinic. The clinical diagnosis was further supported by pancreas pathology (absence of immune infiltrate, presence of islet amyloid). Pancreatic sections from 45 cases (nine lean non-diabetic individuals, 12 lean type 2 diabetic individuals, 11 obese non-diabetic individuals and 13 obese type 2 diabetic individuals) were ultimately included in the study (Table 1). Our interest in pancreatic ductal replication in obesity and type 2 diabetes was because of the potential role chronically increased pancreatic ductal replication may play in the increased risk of pancreatitis and pancreatic cancer in those conditions. For the purposes of comparison we therefore also evaluated ductal replication in nine pancreas samples obtained at surgical resection for pancreatic adenocarcinoma (eight cases) and intraductal papillary mucinous neoplasm (one case). In seven of these cases, the pancreas had no tumour present but all had features of low-grade pancreatitis. In two of the cases the sample of pancreas available contained tumour and the results are reported separately (Table 2).

Case characteristics The lean non-diabetic and lean type 2 diabetic groups were matched for age $(80.1 \pm 3.5$ vs $79.3 \pm$ 2.2 years $)$ and BMI $\left(22.5 \pm 0.7\right.$ vs $\left.22.2 \pm 0.6 \mathrm{~kg} / \mathrm{m}^{2}\right)$. The obese non-diabetic and obese type 2 diabetes groups were also matched for age $(61.5 \pm 4.9$ vs $62.5 \pm 3.7$ years $)$ and BMI $\left(35.3 \pm 2.3\right.$ vs $\left.39.6 \pm 1.9 \mathrm{~kg} / \mathrm{m}^{2}\right)$. The lean non-diabetic and obese non-diabetic cases had similar blood glucose values $(5.5 \pm 0.1$ vs $5.4 \pm 0.1 \mathrm{mmol} / \mathrm{l})$ while the lean and obese cases with type 2 diabetes, by definition, had higher values $(12.4 \pm 0.7$ vs $10.2 \pm 0.9 \mathrm{mmol} / \mathrm{l})$. The treatments of the individuals with type 2 diabetes ranged from diet alone to oral therapy (sulfonylureas) or insulin (Table 1).

Pancreatic tissue processing At autopsy, in all cases, pancreas was resected from the tail and, with a sample of spleen, fixed in formaldehyde and embedded in paraffin for subsequent analysis. Sections, $4 \mu \mathrm{m}$, were cut from the paraffin blocks and stained for haematoxylin/eosin and double-stained for Ki67 (anti-human Ki67 monoclonal antibody MIB-1, 1/25 [Dako, Carpinteria, CA, USA]) and cytokeratin (monoclonal anti-pancytokeratin, 1/50 [SigmaAldrich, St Louis, MO, USA]) by immunohistochemistry.

Analysis The haematoxylin/eosin-stained sections were examined to exclude cases with pancreatitis and autolysis, as per case-selection criteria. Slides double-stained for Ki67, a marker of replication, and cytokeratin, a marker of ductal structures, were examined to determine the percentage of replicating ductal cells. All sections were viewed with an Olympus CX40 microscope (Olympus America, Melville, NY, USA) and images were taken using an Olympus Magnafire SP camera. A mean of $1,243 \pm 62$ duct cells (range 652-3,239) were evaluated per case. To be included 
Table 1 Clinical characteristics of autopsy study subjects

\begin{tabular}{|c|c|c|c|c|c|c|}
\hline Case & Age (years) & Sex & BMI $\left(\mathrm{kg} / \mathrm{m}^{2}\right)$ & FPG (mmol/l) & Treatment & Cause of death \\
\hline \multicolumn{7}{|c|}{ Lean non-diabetic } \\
\hline 1 & 78 & $\mathrm{~F}$ & 17.6 & 5.3 & - & Acute pulmonary embolism \\
\hline 2 & 86 & M & 24.5 & 6.0 & - & Acute aortic rupture \\
\hline 3 & 65 & M & 22.4 & 5.3 & - & Oesophageal haemorrhage \\
\hline 4 & 81 & M & 24.5 & 5.3 & - & Acute myocardial ischaemia \\
\hline 5 & 81 & M & 22.6 & 5.4 & - & Acute myocardial infarction \\
\hline 6 & 87 & M & 24.5 & 4.9 & - & Acute myocardial infarction \\
\hline 7 & 93 & $\mathrm{~F}$ & 23.2 & 5.5 & - & Ruptured dissecting aortic aneurysm \\
\hline 8 & 62 & $\mathrm{~F}$ & 21.3 & 5.4 & - & Acute myocardial ischaemia \\
\hline 9 & 88 & $\mathrm{~F}$ & 22.1 & 6.4 & - & Acute pulmonary embolism \\
\hline Mean & 80.1 & & 22.5 & 5.5 & & \\
\hline SEM & 3.5 & & 0.7 & 0.2 & & \\
\hline \multicolumn{7}{|c|}{ Lean type 2 diabetes } \\
\hline 1 & 83 & M & 21.6 & 12.1 & Diet & Pulmonary embolism \\
\hline 2 & 79 & M & 23.5 & 16.2 & Insulin & Acute myocardial infarction \\
\hline 3 & 69 & $\mathrm{~F}$ & 24.8 & 13.3 & Oral & Arrhythmia, IHD \\
\hline 4 & 83 & $\mathrm{~F}$ & 20.0 & 15.2 & Oral & Adenocarcinoma of breast \\
\hline 5 & 66 & $\mathrm{~F}$ & 22.2 & 9.9 & Oral & Acute myocardial ischaemia \\
\hline 6 & 68 & M & 18.8 & 8.8 & Diet & Heart failure, IHD \\
\hline 7 & 84 & M & 23.7 & 10.9 & Oral & Arrhythmia, IHD \\
\hline 8 & 84 & M & 19.4 & 10.9 & Diet & Acute myocardial infarction \\
\hline 9 & 78 & M & 22.7 & 14.9 & Diet & Septicaemia \\
\hline 10 & 83 & $\mathrm{~F}$ & 22.7 & 14.9 & Diet & Bronchopneumonia, respiratory failure \\
\hline 11 & 85 & $\mathrm{~F}$ & 24.6 & 10.7 & Oral & Bronchopneumonia, respiratory failure \\
\hline 12 & 89 & $\mathrm{~F}$ & 22.7 & 10.8 & Insulin & Acute myocardial infarction \\
\hline Mean & 79.3 & & 22.2 & 12.4 & & \\
\hline SEM & 2.2 & & 0.6 & 0.7 & & \\
\hline \multicolumn{7}{|c|}{ Obese non-diabetic } \\
\hline 1 & 59 & M & 34.8 & 5.4 & - & $\begin{array}{l}\text { Intra-abdominal haemorrhage, psoas } \\
\text { muscle abscess }\end{array}$ \\
\hline 2 & 63 & $\mathrm{~F}$ & 32.2 & 5.2 & - & Arrhythmia, IHD \\
\hline 3 & 52 & M & 35.0 & 6.0 & - & Arrhythmia, acute pulmonary oedema, IHD \\
\hline 4 & 84 & $\mathrm{~F}$ & 33.4 & 5.4 & - & Arrhythmia, IHD \\
\hline 5 & 64 & M & 31.7 & 5.4 & - & Myocarditis \\
\hline 6 & 44 & M & 56.3 & 5.4 & - & Suicide \\
\hline 7 & 75 & $\mathrm{~F}$ & 30.0 & 5.4 & - & Ischaemic colitis, IHD \\
\hline 8 & 71 & $\mathrm{~F}$ & 29.4 & 4.8 & - & Disseminated coagulopathy \\
\hline 9 & 82 & M & 30.3 & 5.9 & - & Acute pulmonary embolus \\
\hline 10 & 50 & $\mathrm{~F}$ & 37.8 & 5.0 & - & Acute pulmonary embolism \\
\hline 11 & 32 & M & 37.7 & 5.5 & - & Motor vehicle accident \\
\hline Mean & 61.5 & & 35.3 & 5.4 & & \\
\hline SEM & 4.9 & & 2.3 & 0.1 & & \\
\hline \multicolumn{7}{|c|}{ Obese type 2 diabetes } \\
\hline 1 & 65 & M & 37.7 & 16.6 & Insulin & Acute pulmonary embolism \\
\hline 2 & 64 & $\mathrm{~F}$ & 34.7 & 11.7 & Insulin & Congestive heart failure, septicaemia \\
\hline 3 & 43 & $\mathrm{~F}$ & 45.6 & 8.4 & Oral & Intracerebral haemorrhage \\
\hline 4 & 43 & M & 30.8 & 8.1 & None & Metastatic osteogenic sarcoma \\
\hline 5 & 85 & $\mathrm{~F}$ & 32.4 & 7.9 & Oral & IHD \\
\hline 6 & 62 & M & 42.3 & 11.7 & Insulin & Arrhythmia, IHD \\
\hline
\end{tabular}


Table 1 (continued)

\begin{tabular}{lccccll}
\hline Case & Age (years) & Sex & BMI $\left(\mathrm{kg} / \mathrm{m}^{2}\right)$ & FPG $(\mathrm{mmol} / \mathrm{l})$ & Treatment & Cause of death \\
\hline 7 & 85 & $\mathrm{M}$ & 34.9 & 5.4 & Oral & Arrhythmia, IHD \\
8 & 58 & $\mathrm{~F}$ & 56.0 & 13.8 & Insulin & Acute intracerebral haemorrhage \\
9 & 66 & $\mathrm{~F}$ & 33.5 & 7.4 & Insulin & $\begin{array}{c}\text { Acute myocardial ischaemia, pulmonary } \\
\text { embolism }\end{array}$ \\
10 & 71 & $\mathrm{M}$ & 43.9 & 5.5 & Oral & Septicaemia \\
11 & 59 & $\mathrm{~F}$ & 42.6 & 11.2 & Insulin & Septicaemia \\
12 & 49 & $\mathrm{~F}$ & 39.2 & 12.1 & Oral & Adult respiratory distress syndrome \\
13 & 63 & $\mathrm{M}$ & 41.1 & 12.7 & Oral & Acute myocardial infarction \\
Mean & 62.5 & & 39.6 & 10.2 & & \\
SEM & 3.7 & & 1.9 & 0.9 & & \\
\hline
\end{tabular}

IHD, ischaemic heart disease

in the study a minimum of 60 ducts per case had to be identified and analysed. If that number could not be identified on a single section, a second, non-adjacent section of pancreas was obtained and stained for analysis. Ducts of all sizes were included in the evaluation; the majority of ducts analysed were less than 35 cells in cross section.

Statistical analysis The data are presented as the mean \pm standard error of the mean. The non-paired Student's $t$ test was used to address the stated hypotheses.

\section{Results}

Duct cell replication Pancreatic duct cell replication was increased tenfold in non-diabetic obese vs non-diabetic lean humans $(0.34 \pm 0.02 \%$ vs $0.03 \pm 0.02 \%, p<0.0001)$, affirming the hypothesis that pancreatic duct cell replication is increased in obesity (Fig. 1). The second hypothesis, that duct cell replication is increased in type 2 diabetes, was evident in lean cases. In lean individuals, the presence of type 2 diabetes was associated with a fourfold increase in duct cell replication $(0.15 \pm 0.02 \%$ vs $0.03 \pm 0.02 \%, p<$ $0.001)$. In obese individuals, the presence of type 2 diabetes was not associated with a significant increase in ductal replication above that already present in obese non-diabetic controls $(0.43 \pm 0.06 \%$ vs $0.34 \pm 0.02 \%, p=\mathrm{NS})$.

Because, on average, obese individuals died at a younger age than the lean individuals, we undertook a further subgroup analysis matching age of death between all groups. Despite the smaller number of cases, the conclusions were unchanged. Ductal replication was still increased in obese vs lean non-diabetic cases $(0.34 \pm 0.05 \%$ vs
Table 2 Clinical characteristics of surgical study subjects

\begin{tabular}{|c|c|c|c|c|c|}
\hline Case & Age (years) & Sex & BMI $\left(\mathrm{kg} / \mathrm{m}^{2}\right)$ & FPG (mmol/l) & Reason for surgery \\
\hline \multicolumn{6}{|c|}{ Pancreatitis and pancreatic cancer (tumour-free sample) } \\
\hline 1 & 56 & $\mathrm{~F}$ & 35.5 & 8.9 & Pancreatic adenocarcinoma \\
\hline 2 & 67 & $\mathrm{M}$ & 23.8 & 4.3 & Pancreatic adenocarcinoma \\
\hline 3 & 70 & $\mathrm{~F}$ & 24.6 & 4.6 & Pancreatic adenocarcinoma \\
\hline 4 & 67 & $\mathrm{~F}$ & 30 & 5.7 & Pancreatic adenocarcinoma \\
\hline 5 & 69 & $\mathrm{M}$ & 31.9 & 8.3 & $\begin{array}{l}\text { Intraductal papillary mucinous } \\
\text { neoplasm }\end{array}$ \\
\hline 6 & 71 & $\mathrm{M}$ & 25.4 & 6.3 & Pancreatic adenocarcinoma \\
\hline 7 & 55 & $\mathrm{M}$ & 27.9 & 4.5 & Pancreatic adenocarcinoma \\
\hline Mean & 65.0 & & 28.4 & 6.1 & \\
\hline SEM & 2.5 & & 1.6 & 0.7 & \\
\hline \multicolumn{6}{|c|}{ Adenocarcinoma (sample with tumour) } \\
\hline 1 & 64 & $\mathrm{M}$ & 30.3 & 5.3 & Pancreatic adenocarcinoma \\
\hline 2 & 64 & M & 20.5 & 14.9 & Pancreatic adenocarcinoma \\
\hline Mean & 64.0 & & 25.4 & 10.1 & \\
\hline SEM & 0 & & 4.9 & 4.8 & \\
\hline
\end{tabular}




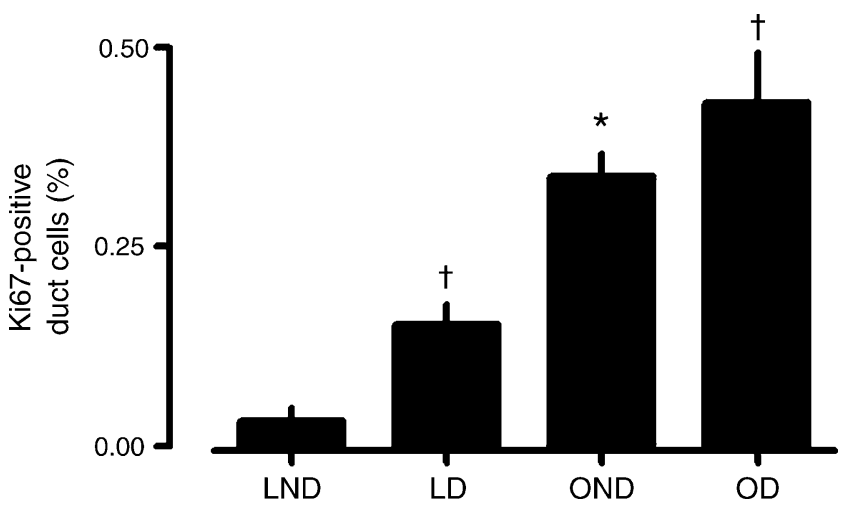

Fig. 1 Percentage of cytokeratin-staining ductal cells positive for Ki67. LND, lean non-diabetic $(n=9)$; OND, obese non-diabetic $(n=$ $11)$; LD, lean with type 2 diabetes $(n=12)$; OD, obese with type 2 diabetes $(n=13)$. Data are presented as mean \pm SEM. $* p<0.0001$, lean non-diabetic vs obese non-diabetic. ${ }^{\dagger} p<0.001$, lean diabetic vs obese diabetic and lean non-diabetic vs lean diabetic

$0.05 \pm 0.02 \%, p<0.001)$, but was not increased in obese type 2 diabetic vs obese non-diabetic individuals $(0.45 \pm$ $0.11 \%$ vs $0.34 \pm 0.05 \%, p=\mathrm{NS}$ ).

When we evaluated tumour-free pancreas samples from individuals with pancreatic tumours and pancreatitis, the frequency of ductal replication was increased further, approximately threefold, compared with the frequency in obese cases with type 2 diabetes. As expected, the frequency of replication in malignantly transformed cells was markedly increased (Fig. 2).

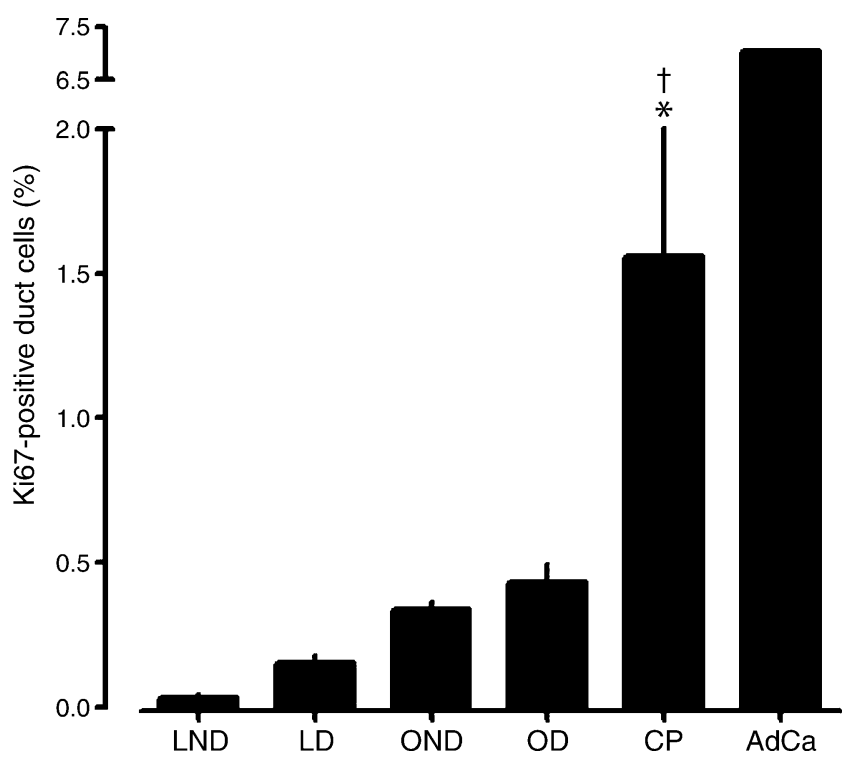

Fig. 2 Percentage of cytokeratin-staining ductal cells positive for Ki67. LND, lean non-diabetic $(n=9) ;$ OND, obese non-diabetic $(n=11)$; LD, Lean with type 2 diabetes $(n=12)$; OD, obese with type 2 diabetes $(n=13)$; CP, chronic pancreatitis in tissue sample $(n=7)$; AdCa, adenocarcinoma present in tissue sample $(n=2)$. Data are presented as mean \pm SEM. ${ }^{*} p<0.005$, lean non-diabetic vs chronic pancreatitis, obese non-diabetic vs chronic pancreatitis, obese diabetic vs chronic pancreatitis. ${ }^{\dagger} p<0.001$, lean diabetic vs chronic pancreatitis

\section{Discussion}

We report that pancreatic duct cell replication is increased in obese humans. Moreover, we report that type 2 diabetes is associated with an increase in duct cell replication that is more obvious in lean than in obese individuals.

Although obesity is recognised as a risk factor for pancreatitis and pancreatic cancer, the mechanisms remain elusive [1]. To our knowledge, this is the first report documenting increased pancreatic duct cell replication in obese and type 2 diabetes patients who do not have histological evidence of pancreatitis. Increased pancreatic duct cell replication is considered a risk factor for pancreatitis and pancreatic cancer [7-9, 11, 12]. We affirm that exocrine ductal replication is increased in pancreas obtained from individuals with pancreatitis associated with pancreatic cancer, and to an even greater extent in malignantly transformed ductal cells (Fig. 2). A limitation of the present study is that pancreas samples from the pancreatic cancer cases were obtained surgically while samples obtained from the other groups were removed at autopsy. To the extent that sensitivity for detection of Ki67 differs between pancreas obtained at surgery vs autopsy, this comparison might be flawed. To limit any effect, pancreas with autolysis was excluded from both groups.

While the current data provide a potential explanation for the increased risk of pancreatitis and pancreatic cancer in obesity and type 2 diabetes, respectively, an obvious limitation of an autopsy study is that it cannot reveal the molecular mechanisms to explain why ductal replication is increased in obesity and type 2 diabetes. Little is known about the regulation of pancreatic duct cell replication. Candidates that might regulate pancreatic duct cell replication include hormones secreted by the gastrointestinal neuroendocrine system in response to food intake, including incretin hormones such as glucagon-like peptide 1 (GLP-1) [13]. While controversial, it has been proposed that exocrine ducts house progenitor cells that are capable of transdifferentiation into endocrine cells to form new islets (so called islet neogenesis) [14]. It is conceivable that obesity and type 2 diabetes promote increased formation of cells from pancreatic progenitors. Treatment of rodents with GLP-1 mimetics or dipeptidyl peptidase-IV inhibitors results in increased islet cell clusters in relation to pancreatic ducts, which is often interpreted as evidence of neogenesis [14].

We observed an increase in pancreatic duct cell replication in the high-fat-fed HIP rat model of type 2 diabetes compared with non-diabetic wild-type rats, and duct cell replication was further increased with treatment with the dipeptidyl peptidase-IV inhibitor sitagliptin [4]. Of concern, we also noted ductal metaplasia in three HIP rats treated with sitagliptin, and pancreatitis in one. These findings led us to 
suggest that the possible link between GLP-1-based therapy and pancreatitis might be an unintended action of GLP-1 to promote pancreatic duct cell replication. GLP-1 receptors are present in pancreatic ducts [4].

In the present study we had no pancreas available to us from humans treated with GLP-1 mimetics or dipeptidyl peptidase-IV inhibitors as these have become available only relatively recently. In the future, it will be important to carefully evaluate the effects of this class of drugs on the exocrine pancreas in humans. In the present study, the individuals with type 2 diabetes had been treated with diet, sulfonylurea or insulin therapy. There was no discernible difference in duct cell replication between these treatments.

In summary, we report that both obesity and type 2 diabetes are associated with increased pancreatic duct cell replication in humans. These data are consistent with the hypothesis that the increased risk of pancreatitis and pancreatic cancer in obesity and type 2 diabetes is driven by chronically increased pancreatic duct cell replication. It will be of interest to establish the signals that foster increased pancreatic duct cell replication in humans. In addition, the present data lend caution to the use of therapeutic strategies that act to increase pancreatic duct cell replication. In HIP rats, GLP-1based therapy appears to provoke increased pancreatic duct cell replication.

Acknowledgements This study was supported by funding from the NIH (DK059579, DK077967) and the Larry L. Hillblom Foundation. We are grateful to our colleagues A. Bhushan and S. Georgia in the Larry Hillblom Islet Research Center for their excellent suggestions. We acknowledge B. Lui for excellent administrative assistance.

Duality of interest The authors declare that there is no duality of interest associated with this manuscript.

Open Access This article is distributed under the terms of the Creative Commons Attribution Noncommercial License which permits any noncommercial use, distribution, and reproduction in any medium, provided the original author(s) and source are credited.

\section{References}

1. Gumbs AA (2008) Obesity, pancreatitis, and pancreatic cancer. Obes Surg 18:1183-1187

2. Gumbs AA, Bessler M, Milone L, Schrope B, Chabot J (2008) Contribution of obesity to pancreatic carcinogenesis. Surg Obes Relat Dis 4:186-193

3. Renehan AG, Tyson M, Egger M, Heller RF, Zwahlen M (2008) Body-mass index and incidence of cancer: a systematic review and meta-analysis of prospective observational studies. Lancet 371:569-578

4. Matveyenko AV, Dry S, Cox HI, Moshtaghian A, Gurlo T, Galasso R, Butler AE, Butler PC (2009) Beneficial endocrine but adverse exocrine effects of sitagliptin in the HIP rat model of type 2 diabetes, interactions with metformin. Diabetes 58:1604-1615

5. Butler AE, Jang J, Gurlo T, Carty MD, Soeller WC, Butler PC (2004) Diabetes due to a progressive defect in beta-cell mass in rats transgenic for human islet amyloid polypeptide (HIP Rat): a new model for type 2 diabetes. Diabetes 53:1509-1516

6. Matveyenko AV, Butler PC (2006) Beta-cell deficit due to increased apoptosis in the human islet amyloid polypeptide transgenic (HIP) rat recapitulates the metabolic defects present in type 2 diabetes. Diabetes 55:2106-2114

7. Willemer S, Adler G (1989) Histochemical and ultrastructural characteristics of tubular complexes in human acute pancreatitis. Dig Dis Sci 34:46-55

8. Bockman DE, Boydston WR, Anderson MC (1982) Origin of tubular complexes in human chronic pancreatitis. Am J Surg 144:243-249

9. Parsa I, Longnecker DS, Scarpelli DG, Pour P, Reddy JK, Lefkowitz M (1985) Ductal metaplasia of human exocrine pancreas and its association with carcinoma. Cancer Res 45:1285-1290

10. Butler AE, Janson J, Bonner-Weir S, Ritzel R, Rizza RA, Butler PC (2003) Beta-cell deficit and increased beta-cell apoptosis in humans with type 2 diabetes. Diabetes 52:102-110

11. Wagner M, Weber CK, Bressau F, Greten FR, Stagge V, Ebert M, Leach SD, Adler G, Schmid RM (2002) Transgenic overexpression of amphiregulin induces a mitogenic response selectively in pancreatic duct cells. Gastroenterology 122:1898-1912

12. Wagner M, Greten FR, Weber CK, Koschnick S, Mattfeldt T, Deppert W, Kern H, Adler G, Schmid RM (2001) A murine tumor progression model for pancreatic cancer recapitulating the genetic alterations of the human disease. Genes Dev 15:286-293

13. Meier JJ, Nauck MA (2006) Incretins and the development of type 2 diabetes. Curr Diab Rep 6:194-201

14. Xu G, Stoffers DA, Habener JF, Bonner-Weir S (1999) Exendin-4 stimulates both beta-cell replication and neogenesis, resulting in increased beta-cell mass and improved glucose tolerance in diabetic rats. Diabetes 48:2270-2276 